\title{
Neuroimagen y alteraciones del funcionamiento cerebral, asociadas al consumo de cocaína
}

\author{
Guardia, J.; Segura, L.; Gonzalvo, B.; Iglesias, L.; Roncero, C. \\ Enviar correspondencia a: \\ José Guardia Serecigni. Unidad de Conductas Adictivas. Servicio de Psiquiatría. Hospital de la Santa Creu i Sant Pau. C/ San Antonio María Claret, 167. \\ 08025 BARCELONA. Tel. 93 2919131. Fax: 93 2919178. E-mail: jguardia@hsp.santpau.es
}

\section{RESUMEN}

El abuso de cocaína puede inducir un deterioro neuro-psiquiátrico de tipo hipofrontalidad, que puede manifestarse clínicamente por desinhibición conductual, inestabilidad emocional, impulsividad, depresión, anhedonia, paranoidismo y deterioro cognitivo.

Mediante las diversas técnicas de neuroimagen estructural se han detectado atrofia y otras altraciones cerebrales. La resonancia magnética espectroscópica ha encontrado indicios de lesión neuronal y proliferación glial, de predominio en el lóbulo frontal.

Las técnicas de neuroimagen funcional han detectado déficits en la perfusión cerebral, que pueden persistir durante meses, después de la desintoxicación, y que se han asociado a la presencia de disfunción cognitiva y otros déficits neuropsicológicos. Además se ha encontrado una reducción de la densidad de receptores dopaminérgicos D2 en el córtex cerebral y una disminución del enlace al transportador de dopamina, en el tálamo y ganglios basales, que podrían estar relacionados con un estado de hipodopaminergia cerebral, debido al consumo crónico de cocaína.

Los citados síntomas cognitivos, afectivos y las alteraciones conductuales que presentan los pacientes dependientes de cocaína, que se encuentran en programa de recuperación, pueden estar relacionados con alteraciones cerebrales orgánicas, inducidas por la propia droga, y pueden aumentar el riesgo de recaída precoz.

Palabras claves: Abuso de cocaína, neuroimagen estructural, neuroimagen funcional, disfunción cognitiva, alteraciones del funcionamiento cerebral.

\section{SUMMARY}

Cocaine abuse can induce neuro-posychiatric impairment, like hypofrontality, that can be shown as clinical symptoms like behavioral desinhibition, emotional instability, impulsivity, depression, anhedonia, paranoid ideation and cognitive impairment.

Structural neuroimage techniques can assess brain shrinking and other structural disturbances. Spectroscopic magnetic resonance has found some signs of neuronal injury and glial proliferation, predominantly in frontal lobes.

Functional neuroimage techniques have found defects in blood brain perfusion, that can be persistent during some months, after detoxification, and that have been associated to the presence of cognitive impairment and other neuropsychological disturbances. Furthermore a reduction in dopaminergic receptor D2 density has been fond in the cerebral cortex and a decrease in the binding to the dopamine transporter, in basal ganglia and thalamus, might be related to a hipodopaminergic state of the brain, due to chronic cocaine abuse.

Cognitive and mood symptoms, and behavioral disturbances shown by cocaine abusers, while in a recovery therapeutic program, can be related to brain organic disturbances, induced by cocaine, and can increase the early relapse risk.

Key words: Cocaine abuse, structural neuroimage, functional neuroimage, cognitive impairment and brain functioning disturbances.

\section{INTRODUCCIÓN}

I abuso de cocaína puede inducir alteraciones del funcionamiento cerebral que van desde trastornos neurológicos, como convulsiones, atrofia cerebral, neuropatía óptica, accidente vascular cerebral (infarto cerebral, hemorragia subaracnoidea e intracerebral, isquemia cerebral multifocal); hasta alte- raciones neuropsicológicas más sutiles que pueden manifestarse como deterioro cognitivo, asociado a alteraciones emocionales y comportamentales, que tienen un trasfondo orgánico.

Mediante el uso de las técnicas de neuroimagen, como resonancia magnética estructural y funcional, tomografía por emisión de positrones y de fotones, se han identificado alteraciones neuroquímicas, fisiológi- 
cas y morfológicas en los abusadores crónicos de cocaína (Majewska, 1996).

Diversos grados de atrofia y lesiones cerebrales, sobretodo en el córtex frontal y ganglios basales, han sido encontradas en dependientes de cocaína (Bartzokis y cols., 1996; Langendorf y cols., 1996). Algunos investigadores han detectado déficits irregulares en la perfusión cerebral en áreas frontales, periventriculares y témporo-parietales en abusadores de diversas sustancias, que aparecerían agravados en los que además toman cocaína (Kosten y cols., 1996). Dichos déficits circulatorios cerebrales pueden aparecer después de la vasoconstricción inducida por cocaína, o pueden ser debidos a un incremento de la agregación plaquetaria y de la coagulación sanguínea (Kosten y cols., 1996).

Se han detectado también alteraciones del metabolismo cerebral de la glucosa en diversas regiones cerebrales, que van en direcciones opuestas en función de que el paciente dependiente de cocaína se encuentre en intoxicación, abstinencia aguda o abstención prolongada de cocaína.

La administración intravenosa de cocaína, en voluntarios sanos, produce una reducción global del metabolismo cerebral de la glucosa en el neocortex, ganglios basales, hipocampo, tálamo y mesencéfalo, que correlacionarían con la euforia, inducida por la administración de cocaína (London y cols., 1996).

En los pacientes dependientes de cocaína, tras la retirada de dicha sustancia, se produce un aumento de la actividad metabólica en regiones corticales orbito-frontales y ganglios basales (Volkow y cols., 1991b) que tiende posteriormente a descender, en el córtex prefrontal, sobretodo en el hemisferio izquierdo (Volkow y cols., 1992a) y se acompaña de un deterioro del flujo sanguíneo cerebral (FSC) que persiste durante 3 a 6 meses, tras la desintoxicación de cocaína (Volkow y cols, 1988).

Los abusadores crónicos de cocaína muestran déficits neurológicos, sobretodo del tipo hipofrontalidad y disfunciones de los ganglios basales, parecidos a los que se han detectado en otros trastornos neurológicos y psiquiátricos, como el hipometabolismo fronto-cortical en la depresión unipolar y bipolar, la hipofrontalidad en la esquizofrenia, o bien en las lesiones del lóbulo frontal debidas a isquemia, convulsiones o accidente vascular cerebral; que suelen ir acompañadas de síntomas de deterioro cognitivo, déficits neuropsicológicos, apatía, depresión y desinhibición social. Todo ello puede contribuir a la aparición de déficits cognitivos, motivacionales, de introspección, desinhibición conductual, déficit de atención, inestabilidad emocional, impulsividad, agresividad, depresión, anhedonia y trastornos motores persistentes.
Este deterioro neuro-psiquiátrico que acompaña al abuso de cocaína es un factor que aumenta la vulnerabilidad para las recaídas, tras un prolongado período de abstención de cocaína, que incluso puede ser una forma de auto-medicación, para compensar los citados déficits neurológicos. En efecto, los pacientes que presentan déficit de atención, depresión o trastorno bipolar, pueden recurrir a los psico-estimulantes, como auto-medicación (Khantzian, 1985).

\section{CORRELATOS NEUROBIOLÓGICOS DE LA DE- PENDENCIA DE COCAÍNA}

Durante la abstinencia aguda de cocaína se produce una alteración de la neurotransmisión que afecta por lo menos a los tres neurotransmisores cuya recaptación inhibe la cocaína (dopamina, serotonina y noradrenalina).

La auto-administración intravenosa de cocaína produce aumentos sostenidos, tanto de dopamina como de serotonina, en las ratas. La abstinencia de cocaína cursa con niveles más bajos de serotonina, en el núcleo accumbens (en animales), lo cual sugiere que la deficiente neurotransmisión serotonérgica puede ser un factor importante en la sintomatología de abstinencia de cocaína.

\subsection{DÉFICIT DE DOPAMINA Y SEROTONINA EN DEPENDIENTES DE COCAÍNA}

El consumo crónico de cocaína conduce a un estado de hipodopaminergia cerebral que se puede manifestar en forma de (1) hiperprolactinemia, sobretodo durante la abstinencia aguda de cocaína, (2) una disminución de la captación de DOPA por las neuronas dopaminérgicas presinápticas del estriado, (3) una reducción de la densidad de receptores dopaminérgicos D2 en el córtex cerebral, evaluada mediante PET (Volkow y cols., 1993); (4) una disminución del enlace de la dopamina a su transportador en los ganglios basales y el tálamo, cuando se comparan los dependientes de cocaína con los sujetos control (Volkow y cols., 1992b). Dichos cambios en la densidad de los transportadores de dopamina podrían tener un carácter dinámico y cambiante, en función del momento en que son estudiados (intoxicación, abstinencia o abstención continuada) (Kosten y cols., 1996).

Dicho estado de hipodopaminergia puede manifestarse clínicamente a través de signos extrapiramidales como movimientos distónicos, coreo-atetósicos, tics o aumento del temblor de reposo en las manos (Bartzokis y cols., 1996); así como también a través de una mayor vulnerabilidad para los efectos extrapiramidales de los fármacos anti-dopaminérgicos. Como que, ade- 
más, está asociado a un bajo nivel de serotonina, puede estar en relación con los estados de anhedonia y desmotivación que aumentan el riesgo de recaída para los pacientes en recuperación.

\subsection{DÉFICITS COGNITIVOS Y COMORBILIDAD PSIQUIÁTRICA}

Los dependientes de cocaína presentan déficits cognitivos, sobretodo de atención, resolución de problemas, abstracción, rendimiento aritmético y memoria a corto plazo, que pueden estar en relación con hipofrontalidad (Majewska, 1996).

En polidrogodependientes se ha encontrado también un aumento de la actividad beta del EEG, en áreas corticales frontales, junto con una amplitud reducida o un retraso de los potenciales evocados. Se trata de patrones característicos del envejecimiento, que ponen en evidencia un deterioro neurológico o bien aceleración del proceso de envejecimiento (Herning y King, 1996).

Los pacientes dependientes de cocaína presentan anhedonia, ansiedad, anergia, paranoidismo, depresión y ciclotimia, que pueden influir sobre los estados de craving, las recaídas y un mayor riesgo de suicidio. Dichos síntomas psiquiátricos tienen una base neuroquímica y persisten durante meses o años después de la retirada de cocaína.

En un estudio efectuado con 300 pacientes dependientes de cocaína, más del 70\% habían presentado algún trastorno psiquiátrico, a lo largo de su vida, tales como alcoholismo, depresión mayor, depresión bipolar, anhedonia, ansiedad, fobias, personalidad antisocial o trastorno por déficit de atención en la infancia (Rounsaville y cols., 1991). La ansiedad, fobias, trastorno por déficit de atención y personalidad antisocial suelen preceder al inicio de la dependencia de cocaína, mientras que el alcoholismo y la depresión suelen aparecer después. Otros autores han encontrado también una elevada prevalencia de trastorno bipolar, ideación suicida, trastorno por estrés post-traumático y trastorno paranoide.

\subsection{ESTRÉSY DEPENDENCIA DE COCAÍNA}

Las ratas sometidas a estrés aprenden a autoadministrarse anfetaminas más rápidamente que las ratas control. Dado que dicho efecto puede ser prevenido mediante adrenalectomía, se ha propuesto que este fenómeno de sensibilización a los estimulantes, inducido por el estrés, puede ser mediado por un aumento de la actividad de las neuronas dopaminérgicas mesencefálicas, inducido por glucocorticoides (Piazza y cols., 1996).

Pero además de la liberación de glucocorticoides, el estrés induce la liberación en el cerebro de determi- nados neuroesteroides, que actúan como moduladores de los receptores GABA-A. Los metabolitos reducidos de la progesterona y desoxi-corticoesterona actúan como agonistas GABA-A, mientras que el sulfato de pregnenolona y el de dehidro-epiandrosterona actúan como antagonistas GABA-A. Dado que el sistema GABA controla la excitabilidad de múltiples neuronas y modula indirectamente diversas funciones del SNC, incluyendo aprendizaje y memoria, los esteroides GABA moduladores, inducidos por estrés, pueden jugar un importante papel para el desarrollo de la dependencia, basado en los procesos de aprendizaje (Majewska, 1996).

\subsection{CAMBIOS EN LA TRANSMISIÓN DOPAMI- NÉRGICA}

La cocaína produce una inhibición de la recaptación, debido a un efecto de bloqueo sobre el transportador de monoaminas (dopamina, noradrenalina y serotonina). El aumento de concentración de dopamina extracelular en el estriado sería el trasfondo neurobiológico del poderoso efecto reforzador de la cocaína.

Sin embargo, el tratamiento crónico con cocaína puede inducir una reducción de la densidad de transportadores de dopamina en regiones mesolímbico/ mesocortical de las ratas, junto con una disminución de la síntesis y liberación de dopamina; que podrían ser indicadores tanto de una regulación descendente compensatoria de los sistemas dopaminérgicos, como de degeneración neuronal (Majewska, 1996).

\subsection{NEUROTOXICIDAD POR COCAÍNA}

Regiones cerebrales ricas en acetilcolina, que se encuentran en una encrucijada entre los sistemas dopaminérgicos, gabérgicos y colinérgicos, son vulnerables a la exposición continuada de cocaína y sus lesiones pueden afectar las funciones neuronales mediadas por dichos neurotransmisores.

La exposición continuada a la cocaína durante 3 a 5 días, según un modelo animal que mimetiza los episodios de consumo descontrolado de cocaína ("binges"), produce una marcada degeneración axonal que se extiende desde la habénula lateral, a lo largo del fascículo retroflejo, hacia el tegmento ventral. Las ratas expuestas a la administración continuada de cocaína presentan cambios en los receptores colinérgicos y gabérgicos, indicadores de lesión de las estructuras post-sinápticas de la neuronas dopaminérgicas. Se trata de cambios neurodegenerativos parecidos a los efectos que producen las amfetaminas, que pueden ser persistentes o incluso permanentes y que pueden estar relacionados con los síntomas psicóticos inducidos por cocaína (Ellison y cols., 1996). 
La cocaína aumenta los niveles extracelulares de catecolaminas, lo cual puede inducir la muerte neuronal en cultivos tisulares, a través de mecanismos de autoxidación, por generación de radicales libres y quinonas tóxicas, en el medio extra-celular.

Además, la vasoconstricción de la circulación cerebral y coronaria, combinada con un aumento de la agregación plquetaria, pueden contribuir a los episodios isquémicos e infartos cerebrales, comprometiendo todavía más el metabolismo energético cerebral, lo cual puede conducir a la neurodegeneración y al desarrollo de edema cerebral. Por otro lado, las hemorragias subaracnoideas e intracerebrales en los dependientes de cocaína pueden conducir a la acumulación de hierro en las membranas neuronales y gliales, lo cual estimula la peroxidación de los radicales libres de los lípidos de la membrana y lesiona la célula (Bartzokis y cols., 1996).

Finalmente, la liberación incontrolada de glutamato, provocada por los episodios isquémicos, es otro factor de neurotoxicidad, ya que produce la entrada masiva de iones calcio que inducen la muerte neuronal (Majewska, 1996).

\subsection{ABUSO DE ALCOHOL Y COCAÍNA}

El abuso simultáneo de alcohol y cocaína conduce a una toma de decisiones más impulsiva y a un rendimiento inferior en los test de aprendizaje y memoria que el que se produce tras el consumo de una u otra sustancias, por separado. Los efectos negativos sobre la capacidad de pensar con claridad persisten durante 1 mes, tras la retirada de ambas sustancias.

El metabolismo de la cocaína y el alcohol dan lugar a la formación de un metabolito más tóxico, el cocaetileno, que tiene una vida media más prolongada y un mayor potencial neurotóxico que cada una de ambas sustancias por separado. Entre las muertes relacionadas con drogas, la combinación más frecuente es la de cocaína y alcohol.

\section{NEUROIMAGEN}

El consumo de cocaína induce cambios metabólicos que se pueden poner de relieve mediante la evaluación del consumo de glucosa, en las diversas regiones cerebrales, y que se pueden correlacionar con otros cambios fisiológicos y determinados estados conductuales.

La tomografía por emisión de positrones (PET), permite obtener una imagen de la actividad metabólica cerebral global o de determinadas regiones que tienen una elevada concentración de receptores dopaminérgicos o bien reciben aferentes del sistema dopaminérgico, mediante la administración del trazador fluorodesoxiglucosa [F18] (FDG), que emite radiaciones gamma. Pero también permite evaluar directamente el funcionalismo dopaminérgico, mediante radiofármacos trazadores que enlazan específicamente con los receptores dopaminérgicos D1 (SCH 23390), con los D2 (raclopride-C11), con el transportador de dopamina (cocaína-C11), o bien con moléculas que permiten evaluar la síntesis del neurotransmisor dopamina ([F18]fluoro-L-dopa) (Volkow, Fowler y Wolf, 1991b).

Se ha hipotetizado que el abuso crónico de cocaína conduce a una deplección de dopamina en la neurona presináptica. Un estudio preliminar ha detectado una disminución en la captación de [F18]fluoro-L-dopa, precursor de la síntesis de dopamina, en el cerebro poco después de la desintoxicación de cocaína, lo cual coincidiría con una disminución en la síntesis de dopamina, en la neurona presináptica.

Por otro lado, los elevados niveles de dopamina en las sinapsis pueden modificar el funcionalismo de los receptores dopaminérgicos. Durante la administración activa de cocaína, o poco después de su retirada, se produce una regulación descendente de los receptores dopaminérgicos post-sinápticos (Volkow, Fowler y Wolf, 1991b).

\subsection{ADMINISTRACIÓN AGUDA DE COCAÍNA}

La administración aguda de cocaína produce una disminución global del metabolismo de la glucosa. La magnitud del cambio metabólico en la amígdala derecha parece seguir una correlación negativa con lo agradable de su efecto y con la intensidad de la respuesta subjetiva (London y cols., 1990; Volkow y cols., 1996b).

La reducción de la tasa metabólica cerebral, que iría en paralelo con el efecto euforizante de la administración aguda de cocaína, podría estar relacionada con la activación del sistema dopaminérgico meso-telencefálico (London y cols., 1996).

Mediante el estudio electroencefalográfico (EEG) se ha encontrado un aumento de la actividad frontal y central, en el rango de frecuencias beta (de 13' 6 a 32'8 hertz). Dado que otras sustancias depresoras del sistema nervioso central (SNC), como los barbitúricos o las benzodiazepinas, también inducen un aumento de la actividad beta EEG, a la vez que disminuyen la tasa metabólica cerebral, parece que tanto el aumento de actividad beta como la disminución de la tasa metabólica pueden estar relacionados con una disminución de la función cortical (London y cols., 1996).

Los efectos reforzadores subjetivos de la cocaína y los cambios en el metabolismo cerebral de la glucosa (mediante PET), correlacionan negativamente con el índice ventrículo cerebral (VBR) de la tomografía cere- 
bral, en poliabusadores de drogas, según el estudio de Morgan y cols. (1993). Los pacientes con ventrículos más agrandados refieren un menor efecto reforzador de la cocaína que los que tienen ventrículos más pequeños, que son los que presentan puntuaciones más elevadas respecto al efecto euforizante o "rush". Dado que se produce una relación inversa entre el tamaño de los ventrículos laterales y la actividad monoaminérgica (dopamina, noradrenalina y serotonina), la baja sensibilidad a los efectos euforizantes de la cocaína, en los abusadores que tienen los ventrículos agrandados, podría ser un reflejo de la patología de las regiones periventriculares, en las cuales se encuentran las estructuras y los circuítos neuroanatómicos mediadores de dichos efectos reforzadores (Morgan y cols., 1993).

\subsubsection{Farmacocinética de la cocaína y metilfeni- dato. Efecto reforzador.}

La cocaína es una de las drogas de abuso que producen un mayor efecto reforzador, el cual parece estar relacionado con su capacidad para bloquear los transportadores de dopamina (TDA) y para aumentar las concentraciones de dopamina en las sinapsis del núcleo accumbens. Sin embargo, otros fármacos tan eficaces como la cocaína para bloquear el TDA, como el metilfenidato, tienen un menor potencial de abuso. Parece que la tasa de entrada al cerebro y de bloqueo delTDA, que tiene cada una de dichas sustancias, es la que determina la intensidad de su efecto euforizante ("high"). En principio se requiere un bloqueo mínimo del 50\% de los TDA para conseguir dicho efecto euforizante, pero además, si el bloqueo es lento, como sucede con el metilfenidato, no se acompaña del efecto euforizante (Volkow y cols., 1999c).

La intensidad del efecto reforzador inducido por metilfenidato correlaciona con la concentración de dopamina liberada, lo cual ha sido medido de manera indirecta, a través de la captación de raclopride por parte de los receptores dopaminérgicos D2 en el estriado. El raclopride es un antagonista competitivo de los receptores D2, que puede ser desplazado por el ligando endógeno (dopamina), cuando su concentración en la sinapsis es elevada. De hecho, la ocupación de los receptores D2 es un mejor predictor de la intensidad del efecto euforizante que los niveles de bloqueo del transportador de dopamina. Tanto la cocaína como el metilfenidato serían más reforzadores en una persona con elevados niveles basales de liberación de dopamina, que en otra con bajos niveles basales de liberación de dopamina (Volkow y cols., 1999d).

Tras la administración de cocaína, se produce un aumento de la oxigenación hemática cerebral (BOLD) en los núcleos accumbens, caudado y córtex insular y una disminución de dicha oxigenación hemática cerebral en la amígdala (Breiter y cols., 1997).
La RMF permite obtener muchas imágenes durante un breve período de tiempo, hacer por tanto un seguimiento paso a paso de los cambios en la actividad cerebral. La tasa de oxigenación hemática cerebral (BOLD), tras la administración de cocaína, va en paralelo con la sensación subjetiva de euforia, y correlaciona positivamente con un pico de activación y un rápido descenso a los niveles previos. El "craving" correlaciona positivamente con una activación sostenida del núcleo accumbens, región subcallosa y cerebro anterior basal y negativamente con la amígdala (Breiter y cols., 1997).

La administración intravenosa de metilfenidato induce una activación del metabolismo cerebral de la glucosa en la circunvolución del cíngulo anterior, tálamo derecho y cerebelo. Además, la activación del córtex fronto-orbitario derecho y núcleo caudado derecho correlacionaron positivamente con el "craving" de cocaína (Volkow y cols., 1999b).

En otro estudio de Volkow y cols., (1997b) los efectos de placer o recompensa cerebral, inducidos por metilfenidato, van asociados a la liberación de dopamina, la cual desplaza el radiofármaco raclopride- $C^{11}$ de su enlace con los receptores dopaminérgicos D2.

Los abusadores de cocaína presentaron una menor liberación de dopamina en el estriado (sobretodo en caudado) pero un aumento de su liberación en el tálamo, que correlacionó positivamente con el craving de cocaína Volkow y cols., (1997b).

\subsubsection{Efectos de la cocaína sobre la circulación cerebral}

La cocaína y sus metabolitos son potentes vasoconstrictores cerebrales en los modelos animales (Madden y cols., 1995). La administración de cocaína intravenosa produce un aumento de la frecuencia cardíaca y la presión arterial, entre 6 y 10 minutos después de su administración, que permanece elevada 20 minutos más tarde y se acompaña de vasaoconstricción de la arteria cerebral posterior y media, arterias verterbrales y comunicantes posteriores.

El consumo de cocaína induce una vasoconstricción de las arterias cerebrales y, por tanto, una reducción de la perfusión cerebral en diversas regiones, de la misma manera que en la circulación coronaria.

Los efectos tóxicos más comunes de la cocaína implican las consecuencias cardiovasculares y neurovasculares, tales como hemorragias cerebrales parenquimatosas, subaracnoideas y manifestaciones isquémicas cerebrals. Las alteraciones vasculares subyacentes asociadas a la hipertensión sistémica pueden conducir al accidente vascular cerebral (AVC) hemorrágico (Johanson y Schuster, 1995).

Utilizando resonancia magnética con angiografía (RMA) se ha comprobado que la administración de 
cocaína, a dosis bajas, induce una vasoconstricción cuya probabilidad de aparición estaría relacionada con el tiempo de consumo de cocaína, a lo largo de toda la vida. Dicho efecto se produce sin que concurran otros factores de riesgo, como abuso de otras drogas, hipertensión arterial o enferemedad cerebro-vascular, lo cual sugiere que la cocaína puede tener un efecto acumulativo residual en el desarrollo de la citada disfunción cerebro-vascular (Kaufman y cols., 1998).

El consumo crónico de cocaína se asocia a defectos focales de perfusión cerebral, que se han ido asociando a la presencia de disfunción cognitiva (Volkow y cols., 1998; Holman y cols., 1991; Strickland y cols., 1993). Unos y otros persisten durante los períodos de abstención de cocaína, lo cual sugiere que la disfunción cerebral se produce y mantiene más allá del período de intoxicación aguda de cocaína.

Dosis relativamente bajas de cocaína pueden inducir cambios angiográficos en personas sanas, indicadores de vasoconstricción cerebral, que son dosis-dependientes, que pueden llevar a una hipoperfusión (Davis y cols., 1992) y que si son persistentes pueden estar asociados a disfunción neuronal.

La disfunción cognitiva observada en abusadores crónicos de cocaína está relacionada con la cantidad de cocaína consumida (O'Malley y cols., 1992), lo cual sugiere un efecto residual acumulativo de la cocaína sobre la función cerebral, que puede empezar a partir de 5-10 exposiciones previas a dicha sustancia y que puede conducir al accidente vascular cerebral. Es posible que el consumo previo de cocaína aumente la propensión para experimentar vasoconstricción cerebral. Los metabolitos de la cocaína, que pueden persistir en las horas posteriores al consumo de cocaína, pueden contribuir a que la vasoconstricción cerebral y la disminución de la perfusión cerebral asociadas, sean prolongadas. Finalmente, la activación de la función cardiovascular también puede contribuir a la vasoconstricción cerebral (Kaufman y cols., 1998).

Volkow y cols., (1988) detectaron una reducción del flujo sanguíneo cerebral (FSC) en determinadas áreas del cerebro, que persistía 10 días después del cese del consumo de cocaína; sugiriendo que puede ser debido a cambios en el funcionamiento neuronal, indicadores de neurotoxicidad sobre las neuronas dopaminérgicas. Siguiendo la misma hipótesis, la disminución de la actividad dopaminérgica podría explicar el aumento del metabolismo de la glucosa, en el córtex órbito-frontal y ganglios basales, tras cesar el consumo de cocaína (Volkow, Fowler y Wolf, 1991).

Strickland y cols., (1993; 1996) confirmaron la persistencia de déficits en el flujo sanguíneo cerebral (FSG) hasta 6 meses después del cese del consumo de cocaína, asociados a déficits de atención, memoria, formación de conceptos, flexibilidad mental y desinhibición, es decir, dificultades para inhibir con- ductas inapropiadas, en los tests neuropsicológicos. Las dificultades de atención o memoria o la desinhibición conductual pueden impedir que estos pacientes se beneficien de la psicoterapia convencional (Strickland y cols., 1993).

El abuso crónico de cocaína puede conducir a un accidente vascular cerebral (AVC) y a déficits de perfusión cerebral de larga duración, a través de una aceleración del proceso de ateroesclerosis de las arterias cerebrales que aumenta la propensión al vasoespasmo, un estado de vasoconstricción que dura minutos, más que segundos.

El vasoespasmo podría lesionar la capa interna del vaso, promoviendo un mayor desarrollo de la ateroesclerosis, con lo cual se crearía una espiral de empeoramiento progresivo, formando parte de un proceso de aterosclerosis. La administración de ácido acetil-salicílico, que inhibiría la formación de coágulos, ha sido propuesto para prevenir dsichaas comnplicaciones.

Los datos obtenidos mediante sonografía doppler transcraneal (SDT) sugieren que los abusadores de cocaína, de 30 a 40 años de edad, tienen un grado de vasoconstricción arterial cerebral parecido al de personas de más de 60 años (Herning y cols., 1997). La SDT es una técnica de exploración rápida, sencilla y económica que puede repetirse con frecuencia y que permite monitorizar la recuperación, cuando el paciente empieza a tomar mediacación.

\subsection{RETIRADA DE COCAÍNA}

\subsubsection{Metabolismo cerebral}

La abstinencia aguda de cocaína (menos de una semana), se ha asociado a un incremento de la tasa metabólica en el córtex orbito-frontal y en los ganglios basales, mientras que a las 2 a las 4 semanas después de la retirada de cocaína se produce una recuperación de la tasa metabólica normal, mediante tomografía por emisión de positrones (PET) con fluoro-desoxi-glucosa (FDG). Se ha sugerido que estos elevados niveles de metabolismo cerebral en los ganglios basales y córtex orbitofrontal pueden ser consecuncia de una menor actividad dopaminérgica cerebral (Volkow, Fowler y Wolf, 1991a; London y cols., 1996).

Pero la abstención más prolongada, entre 1 y 6 semanas, después del cese del consumo de cocaína, cursa con una baja tasa metabólica en el córtex frontal, que persistía en los pacientes que volvieron a ser explorados 3-4 meses después (Volkow y cols., 1992a: London y cols., 1996b).

Además, tras el consumo crónico de cocaína se produce una disminución de receptores dopaminérgicos D2 que está asociada a la disminución de metabolismo en la circunvolución del cíngulo y en el córtex órbito-frontal. Volkow y cols. (1999c), postulan que 
este sería uno de los mecanismos de alteración dopaminérgica que conducirían al consumo compulsivo de cocaína y a su dependencia. La dopamina, en los circuítos frontales, está implicada en el control de las conductas repetitivas e impulsivas. Los dependientes de cocaína presentan cambios neuroquímicos que pueden ser el trasfondo neurobiológico de su incapacidad para controlar los impulsos que les arrastran a consumir la droga y que podrían explicar las recaídas (Volkow y cols., 1996b)

Por otro lado, los abusadores de cocaína presentan una disminución de la liberación de dopamina, que asociada a la reducción de receptores D2 puede resultar en una disminución de la activación de los circuítos de recompensa cerebral por los reforzadores fisiológicos, contribuyendo a generar el estado de "necesidad" de administrarse cocaína para compensar dicho déficit (Volkow y cols., 1999c).

\subsubsection{Flujo sanguíneo cerebral (SPECT de per- fusión)}

Estudios efectuados con pacientes dependientes de cocaína han encontrado alteraciones en la perfusión sanguínea de los córtex parietal, temporal, frontal y de los ganglios basales, aunque ni la cantidad ni la frecuencia del consumo previo de cocaína estaban asociados al número ni al tamaño de dichos defectos focales de perfusión pero sí lo estaba el consumo de alcohol asociado (Holman y cols., 1991). Los déficits de perfusión serían más frecuentes en los pacientes con dependencia asociada de alcohol u opioides que en los que sólo presentaban dependencia de cocaína. El alcaloide cocaetilino, debido a la asociación de metabolitos de ambas sustancias, potenciaría los efectos cardio-vasculares de la cocaína, alcanzando tasas más elevadas y persistentes de taquicardia e hipertensión arterial (McCance-Katz y cols., 1993). Por tanto el abuso de alcohol, en el contexto de la dependencia severa de cocaína puede predisponer al desarrollo de los citados déficits de perfusión (Kosten, Malison y Wallace, 1996).

El tratamiento con bupernorfina (agonista/antagonista opioide), asociado a la abstención de cocaína, parece producir una mejora en la perfusión cerebral de estos pacientes (Holman y cols., 1993).

Diversos mecanismos podrían contribuir a los citados defectos de perfusión sanguínea. Dosis elevadas de cocaína pueden producir vasoconstricción cerebral severa y persistente, con déficits de perfusión que pueden incluso inducir muerte neuronal. Por otro lado las plaquetas de los consumidores crónicos de cocaína se encuentran parcialmente activadas y cualquier estímulo puede producir la liberación de gránulos que contribuyen a la agregación plaquetaria y a la formación de trombos en los vasos sanguíneos cerebrales de pequeño calibre (Kosten, Malison y Wallace, 1996).

\subsubsection{Lesión neuronal. Resonancia magnética espectroscópica}

La RMS puede evaluar cambios neuroquímicos, a través de determinados metabolitos cerebrales, como el N-acetilaspartato, un mrcador neuronal; glutamato y glutamina, neurotransmisores excitadores; creatina y fosfocreatina, indicadores del metabolismo energético; compuestos que contienen colina, relacionados con la membrana neuronal y mioinositol, un marcador glial.

Después de 5 meses de abstención de cocaína se han detectado alteraciones persistentes en los lóbulos frontales de cocainómanos abstinentes, con una disminución de los compuestos $\mathrm{N}$-acetilados en la sustancia gris frontal, indicadora de lesión neuronal en el córtex frontal, debido al consumo de cocaína "crack".

Tanto hombres como mujeres presentaban aumento de la concentración de mioinositol en sus lóbulos frontales, que serían indicadores de hipertrofia o bien proliferación glial. Dicho incremento de la actividad glial implica un proceso reactivo en el cerebro y ha sido detectado también en otras encefalopatías y tras el consumo crónico de anfetaminas (MDMA). Dicha gliosis podría explicar también el aumento de creatina en la sustancia blanca.

Es decir, que el consumo crónico de cocaína está asocido con lesión neuronal, que se caracteriza por una disminución de compuestos $\mathrm{N}$-acetilados en el córtex frontal y por proliferación glial (aumento de mioinositol) tanto en la sustancia gris, como blanca frontales, que serían más acusados en los hombres; mientras que las mujeres presentaban un mayor incremento de mioinositol en la sustancia blanca frontal. Por tanto, existen diferencias regionales y entre sexos, con referencia a la concentración de los citados metabolitos cerebrales. (Chang y cols, 1999).

Estos hallazgos estarían también en concordancia con la disminución de receptores dopaminérgicos, asociada a hipometabolismo en los lóbulos frontales, encontrada en otros estudios (Volkow y cols., 1990; 1993).

Las mujeres dependientes de cocaína presentan menos alteraciones de la perfusión cerebral frontal y obtienen mejores resultados de tratamiento que los hombres dependientes de cocaína.

Es decir, que las alteraciones asociadas al abuso de cocaína, que aparecen en neuroimagen, pueden ser persistentes y variar en función del sexo.

\subsubsection{Déficits neuropsicológicos en correlación con neuroimagen}

Existen dos amplias categorías de alteraciones neuropsiquiátricas en la dependencia de cocaína. Por un lado están los trastornos afectivos y de ansiedad, 
como el trastorno por crisis de angustia, que puede persistir años después de haber dejado de tomar cocaína. Por otro lado están los déficits cognitivos, detectados hasta 18 meses después de retirar la cocaína, con dificultades en las tareas que requieren concentración y memoria reciente (O'Malley y cols., 1992) y alteraciones en tareas motoras, que sugieren síntomas parkinsonianos (Bauer 1993).

Holman y cols. (1991; 1993) no han encontrado correlación entre los déficits neuropsicológicos específicos y las áreas neuroanatómicas con una perfusión cerebral alterada, pero los pacientes que presentaban un déficit en la perfusión cerebral mostraron también un deterioro neuropsicológico en diversos tests, sobretodo en aprendizaje espacial y organización. Por tanto, no parece que exista una correlación precisa pero sí que se produce una asociación entre el deterioro psicológico en memoria/atención y la presencia de múltiples déficits de perfusión cerebral (Kosten, Malison y Wallace, 1996).

En un estudio efectuado mediante SPECT de perfusión, con abusadores de cocaína que habían permanecido abstinentes los 6 meses previos a la exploración, se encontraron déficits persistentes de flujo sanguíneo, que podrían ser incluso permanentes. Además, la exploración neuropsicológica reflejaba déficits de atención, memoria, formación conceptual y flexibilidad mental, con dificultades para inhibir las conductas inapropiadas, lo cual recibe el nombre de desinhibición conductual (Strickland y cols., 1993).

\subsection{CRAVING}

Los estímulos condicionados al consumo de cocaína pueden disparar estados de "craving", en los pacientes dependientes, que se acompañan de una activación límbica que se manifiesta por un aumento del FSC en la amígdala y la circunvolución cingulada anterior y de una disminución del FSC en los ganglios basales, mediante PET. Por tanto, la activación límbica sería un componente del craving de cocaína, inducido por estímulos condicionados (Childress y cols., 1999).

Los agentes anti-craving que ejerzan una acción de bloqueo de los receptores dopaminérgicos del sistema límbico, como los antagonistas dopaminérgicos, podrían reducir la respuesta de craving inducida por estímulos condicionados Pero el aplanamiento afectivo y motivacional que inducen algunos de ellos contribuye a un bajo cumplimiento, por parte del paciente.

En un estudio efectuado con PET se detectó un incremento de la actividad metabólica en el córtex prefrfontal dorso-lateral y en región medial del lóbulo temporal, tras la exposición a estímulos condicionados, relacionados con cocaína (Grant y cols., 1996).

En otro estudio efectuado con la técnica de activación funcional dependiente del nivel de oxigenación de la sangre (DNOS), que pertenece a un tipo de resonancia magnética funcional, se ha comprobado que los niveles de craving auto-referidos por dependientes de cocaína, expuestos a estímulos condicionados, correlacionan con la activación del córtex cingulado anterior y prefrontal dorso-lateral izquierdo, en comparación a personas no drogodependientes. La resonancia magnética funcional (RMF) proporciona una elevada resolución espacial y temporal. Como ventajas sobre PET o SPECT, la RMF no requiere trazadores radiactivos, por tanto, resulta menos invasiva y se puede repetir varias veces en una misma persona, en diferentes momento evolutivos de su dorogodependencia (Maas y cols., 1998) (Tabla 1).

Volkow y cols. (1999a) concluyen, a partir de sus estudios con cocaína, que:

(1) El aumento de liberación de dopamina no es suficiente, por si mismo, para inducir un aumento del metabolismo frontal. (2) El "craving" de cocaína podría estar asociado a una activación metabólica del córtex fronto-orbitatrio y del estriado. (3) El circuíto estriado-frontorbitario está implicado en la prominencia de los estímulos reforzadores y su activación puede ser uno de los mecanismos asociados a la pérdida de control y a la administración compulsiva de drogas. (4) La activación por la dopamina de la circunvolución del cíngulo, una región cerebral implicada en el "drive" o motivación, podría contribuir al deseo de tomar más cocaína, durante la estimulación dopaminérgica, inducida por cocaína. (5) La correlación predominante del "craving" con el hemisferio derecho, pero no con el izquierdo, requiere profundizar en la investigación, para comprobar la posible lateralidad de las respuestas reforzadas o condicionadas a las drogas.

\subsubsection{Estructuras cerebrales implicadas en el craving de cocaína}

Los estudios de neuroimagen con abusadores de cocaína han identificado estructuras cerebrales implicadas en el "craving." Los que inducen "craving" mediante la administración de cocaína refieren una aumento de la actividad del tálamo, mientras que los que utilizan estímulos condicionados visuales reportan aumento de la actividad del córtex frontal dorso-lateral, que se suele activar con las tareas relacionadas con memoria de trabajo (almacenamiento de información a corto plazo) y memoria episódica (evocación de secuencias de acontecimientos pasados) debido a que el craving incentivo, basado en estímulos sensoriales, requiere la activación de determinados circuítos de memoria, lo cual no sucede con el craving inducido por la propia droga, que tal vez convendría diferenciar del craving condicionado, mediante otra denominación y que podría estar más cercano al llamado efecto "priming".

Las estructuras activadas por el "craving", es decir, los núcleos caudado, accumbens, tálamo, amígdala, 
córtex orbitario, córtex frontal dorso-lateral, córtex cingulado anterior y córtex insular; forman parte del llamado circuíto estriado-talámico-cortical, que estaría implicado en funciones emocionales, motivacionales y de conducta social (Hommer y cols., 1999).

El córtex insular está relacionado con funciones viscerales, sensoriales y emocionales. El córtex cingulado anterior está implicado en la regulación de la atención y emoción y puede ser especialmente importante para el prendizaje de asociaciones entre determinados estímulos y recompensas.

La amígdala es un relevo de información sobre estímulos asociados tanto a la recompensa como al castigo que se dirigen hacia el córtex orbitario. Tiene una importancia decisiva para el aprendizaje de relaciones entre los estímulos biológicamente relevantes (comida, compañeros sexuales, dolor, etc.) y las señales relacionadas con ellos. En estudios animales se ha comprobado que juega un papel similar en el procesamiento de señales relacionadas con cocaína. La circunvolución cingulada anterior comparte conexiones recíprocas con la amígdala y juega un papel importante en la respuesta emocional y en la atención selectiva. Ambas estructuras están vinculadas anatómicamente con el núcleo accumbens, una región cerebral importante para las propiedades reforzadoras de la cocaína y para la recompensa natural en animales. Dichas estructuras permiten al organismo no sólo experimentar el placer de la recompensa, sino también aprender las señales anunciadoras que anticipan la recompensa y que pueden ser de gran importancia para la supervivencia individual o de la especie. Durante los estados de "craving", inducidos por estímulos condicionados, el drogodependiente se siente apasionadamente arrastrado por un estado emocional visceral y experimenta un incentivo para actuar muy focalizado, que en aquel momento no le permite recordar las consecuencias negativas del consumo de de cocaína (Childress y cols., 1999).

El cerebelo, aunque está implicado en la psicomotricidad, puede intervenir también en las propiedades reforzadoras de los reforzadores naturales y de las sustancias psicotrópicas. Tiene conexiones con regiones límbicas cerebrales y su activación podría estar directamente relacionada con la recompensa cerebral. Tanto los psicoestimulantes como el cannabis pueden producir activación del cerebelo, que ha sido asociada a estados de "craving", inducidos por cocaína.

El córtex fronto-orbitario procesa información sobre estímulos reforzadores y aversivos y estaría implicado en los cambios de conducta, cuando se producen modificaciones de las características reforzadoras de dichos estímulos. También se ha relacionado con la expectación del estímulo condicionado, que puede ser percibida conscientemente como "craving". Las lesiones en la región fronto-orbitaria comportan déficits conductuales parecidos a las lesiones del estriado, resultando en perseveración y resistencia a la extinción de las conductas asociadas a la recompensa. Se ha comprobado que dicha patología es patente en la región fronto-orbitaria y el estriado de los pacientes con trastorno obsesivo-compulsivo. La activación del córtex fronto-orbitario y del estriado por metilfenidato, en pacientes dependientes de cocaína, podría ser uno de los mecanismos por los cuales cocaína elicita "craving" y la subsiguiente administración compulsiva de la sustancia (Volkow y cols., 1999b), que pueden llevar a la recaída a un paciente en curso avanzado de recuperación (Tabla 2).

\subsection{RECEPTORES Y TRANSPORTADORES DE DOPAMINA}

\subsubsection{Receptores dopaminérgicos post-sinápti- $\cos$}

La cocaína inhibe la función del transportador de dopamina, evitando su recaptación y facilitando su acumulación en el espacio sináptico, lo cual puede inducir una regulación descendente de los receptores dopaminérgicos, como neuroadaptación al estado de excesiva estimulación.

Los estudios con animales han confirmado la regulación descendente de los receptores post-sinápticos D1 pero no de los D2. Algún estudio de neuroimagen, mediante PET ha encontrado una reducción de los receptores D2, durante la abstinencia aguda de cocaína (Volkow y cols., 1990), pero no ha sido confirmado por otro estudio, mediante SPECT con yodobenzamida (IBZM), en pacientes dependientes de cocaína que habían permanecido abstinentes (Childress, 1995).

Estudios con PET han encontrado una correlación inversa entre humor depresivo y receptores D2 postsinápticos, del estriado, en pacientes dependientes de cocaína (Volkow y cols., 1990) Dicha disfunción dopaminérgica podría ser el trasfondo neurobiológico de la disforia y anhedonia post-cocaína que aumenta la vulnerabilidad del paciente para la recaída (Malison y cols., 1998).

Mediante la utilización de la PET con radiofármacos trazadores, se ha encontrado una disminución del número de receptores D2, que persiste después de la desintoxicación y que se asocia a una disminución de la actividad metabólica del córtex prefrontal, circunvolución del cíngulo y córtex fronto-orbitario (Volkow y cols., 1993a).

Tras la administración de anfetamina se producen síntomas de euforia, estados de alerta, inquietud y ansiedad. EI SPECT con IBZM detecta una disminución de la disponibilidad de receptores D2, debido a la liberación de dopamina endógena, que correlaciona con la intensidad de los citados síntomas (Laruelle y cols., 1995); resultados parecidos a los que se obtinene utilizando PET con raclopride. 
(Volkow y cols., 1999a), comprueban que los sujetos sanos que refieren un efecto reforzador, tras la administración de metilfenidato, presentan menor captación de raclopride, es decir, niveles más bajos de receptores D2, mientras que el subgrupo de sujetos que refiere efectos más bien desagradables son los que presentan una elevada captación de raclopride que vendría a reflejar elevados niveles de receptores D2. Es decir, que el nivel de receptores D2 podría predecir la respuesta reforzadora de los psicoestimulantes y un bajo nivel de receptores D2 podría contribuir al abuso de psicoestimulantes ya que favorecería el efecto placentero de dichas sustancias (Volkow y cols., 1999a).

Se ha propuesto que existiría un rango óptimo de estimulación del receptor D2 para la producción de efectos reforzadores. Por debajo, la estimulación sería insuficiente para inducir efectos reforzadores y por encima produciría efectos aversivos. Es posible que en los sujetos con un elevado número de receptores D2, una pequeña dosis de metilfenidato pueda ser percibida como agradable, pero una dosis elevada podría resultar incluso desagradable. Si el nivel de receptores D2 modula la sensibilidad de los reforzadores fisiológicos, se podría postular que un bajo nivel de receptores D2 podría predisponer hacia el abuso de drogas, mientras que un elevado nivel de receptores D2 podría proteger contra dicho abuso de drogas, ya que podría inducir respuestas desagradables a la drogas.

De hecho, los ratones tratados genéticamente que carecen de receptores D2 presentan una disminución de los efectos reforzadores del alcohol y la morfina y el bloqueo de dichos receptores, mediante fármacos antidopaminérgicos, produce una disminución de los efectos reforzadores de la cocaína, en animales, mientras que en humanos los resultados no han sido tan concluyentes, tal vez porque las dosis empleadas son menores que en los estudios con animales (Volkow y cols., 1999a).

\subsubsection{Transportador de dopamina.}

El lugar de acción preferente y más claramente implicado en el potencial adictivo de la cocaína es el transportador de dopamina. Estudios post-mortem en humanos han detectado un aumento de los lugares de enlace al transportador de dopamina, entre abusadores de cocaína que fallecieron por sobredosis (Staley y cols., 1994). Los estudios de neuroimagen, mediante SPECT con b CIT, un análogo a la cocaína, han encontrado también un aumento de los lugares de enlace al transportador de dopamina (TDA) del estriado de los pacientes dependientes de cocaína (Kosten, Malison y Wallace, 1996; Malison y cols., 1998; Little y cols., 1999).
No se trata de un aumento de la afinidad del transportador de dopamina sino de un incremento del número de lugares de enlace en las neuronas dopaminérgicas, a pesar del aparente menor número de terminales dopaminérgicos totales.

Dicho aumento de los lugares de enlace en el transportador de dopamina del estriado que podría aparecer tras un episodio de consumo descontrolado de cocaína ("binge"), podría estar relacionada con la anhedonia por abstinencia y el "craving" de cocaína. Pero parece estar asociada a una disminución de los niveles de ARN mensajero del transportador de dopamina, debido a una pérdida de neuronas dopaminérgicas (Little y cols., 1998).

La hipercaptación del transportador de dopamina tarda unas 2-4 semanas en renormalizarse, tras abandonar el consumo de dicha sustancia, lo cual coincidiría con el tiempo de remisión de la sintomatología depresiva y el trastorno del sueño, en el proceso de recuperación, desde que el paciente deja de tomar cocaína (Kosten, Malison y Wallace, 1996).

También han aparecido resultados en sentido contrario, es decir una reducción del número de lugares de enlace para el transportador de dopamina en el córtex prefrontal de los abusadores de cocaína, en un estudio post-mortem (Hitri y cols., 1994) y también en un estudio post-desintoxicación, mediante PET (Volkow y cols., 1996b). Pero podrían ser atribuíbles al alcoholismo comórbido, el cual podría contribuir a dicha reducción de los lugares de enlace para el transportador de dopamina (Little y cols., 1999).

\subsubsection{Transportador de serotonina}

Se ha encontrado un aumento de captación de bCIT (mediante SPECT) por parte del transportador de serotonina, en el tronco cerebral y diencéfalo, lo cual apoya el papel de la serotonina (además del de la dopamina), en los cambios neuroadaptativos, debidos al consumo de cocaína. Dicho aumento de lugares de enlace al transportador de serotonina parece tener correlación inversa con la edad, lo cual podría explicar la baja respuesta a los inhibidores de recaptación de serotonina de algunos pacientes ancianos que presentan depresión (Jacobsen y cols., 2000)

La inhibición crónica del transportador de monoaminas, por parte de la cocaína, puede inducir una regulación ascendente compensatoria de dicho transportador. Otra hipótesis alternativa sería que la mayor disponibilidad de transportadores de sorotonina, en el tronco cerebral, podría ser debida a una disminución de serotonina en las sinapsis, secundarios al consumo crónico de cocaína.

El referido aumento de captación de b CIT, durante la abstinencia aguda de cocaína, no puede ser atribuíble a un posible abuso de alcohol asociado, ya que los 
pacientes alcohólicos presentan más bien una disminución de la captación de b CIT (Jacobsen y cols., 2000).

Como contrapartida, algún estudio post-mortem ha encontrado una disminución de los lugares de captación del transportador de serotonina, mediante el radioligando b CIT, en abusadores de cocaína y opiáceos (Little y cols., 1998). Pero que parece estar más en relación con los opiáceos que con la cocaína, ya que, las víctimas de sobredosis de cocaína presentan un aumento de captación por el transportador de serotonina en regiones del estriado y córtex.

\subsection{NEUROIMAGEN ESTRUCTURAL}

La atrofia cerebral es una posible consecuencia del abuso de alcohol, inhalantes, corticoesteroides y ácido valproico. Estudios efectuados con abusadores de múltiples drogas, mediante resonancia magnética estructural (RME), han encontrado una mayor amplitud del tercer ventrículo y del vermis cerebeloso, pero únicamente la severidad del abuso de alcohol pudo ser correlacionada con dichos índices de atrofia cerebral, tras haber tenido en cuenta el efecto de la edad.

Otros estudios, con muestras de abusadores de cocaína han detectado una correlación entre la duración del abuso de cocaína y la amplitud máxima de las astas frontales de los ventrículos laterales, sugiriendo una relación dosis-efecto.

Los resultados preliminares del estudio BADACO, sobre la atrofia cerebral y sus consecuencias funcionales, apuntan a que el abuso crónico de cocaína induce atrofia cerebral que se asocia a disfunción cognitiva y electrofisiológica. Sugieren que la base patogénica para la atrofia sería la isquemia cerebral y sus consecuencias son parcialmente reversibles, mediante la abstinencia de cocaína. Los estudios con SPECT han encontrado déficit de perfusión cerebral en los abusadores de cocaína, pero con frecuencia, no aparecen asociados a la atrofia cerebral, detectada mediante RME o bien tomografía cerebral. Otros factores etiopatogénicos, además del factor isquémico cerebral, serían los propios efectos citotóxicos directos de la cocaína, lesiones cerebrales menores, déficits nutricionales, estrés, otros factores relacionados con el estilo de vida del dependiente de cocaína y factores genéticos de vulnerabilidad, mediadores del volumen del cerebro en los drogodependientes (Langendorf y cols, 1996).

Los estudios efectuados en dependientes de cocaína, mediante resonancia magnética estructural (RME) y tomografía cerebral (TC), han reportado un aumento de la relación entre la anchura de los ventrículo y la de todo el cerebro (llamada tasa ventrículo-cerebral) (Pascual-Leone y cols., 1991; Morgan y cols., 1993). También se han encontrado lesiones cerebrales debidas a un accidente vascular cerebral que puede haber pasado desapercibido.

Cambios patológicos tisulares, debidos a neurotoxicidad por abuso de cocaína, pueden inducir un aumento del contenido de agua en los tejidos cerebrales que pueden hacerse evidentes mediante un enlentecimiento del tiempo de relajación transverso (T2) de la RME. También pueden aparecer pequeñas imágenes hiperintensas que corresponden a lesiones del estriado, en los cortes coronales, que corresponden al territorio de las ramas antero-laterales de las arterias cerebrales media y anterior, que con frecuencia presentan hemorragias en los pacientes dependientes de cocaína.

Los resultados preliminares del estudio AIMS han encontrado correlaciones casi estadísticamente significativas entre la presencia de movimientos coreo-atetoides y el tiempo de relajación T2 del putamen, sobretodo en el hemisferio derecho, en el cual llega a alcanzar la significación estadística (Bartzokis, Beckson y Ling, 1996). La neurotoxicidad del abuso de cocaína sobre los ganglios basales puede manifestarse a través de síntomas clínicos sutilies, como déficit de concentración o memoria (O’Malley y cols., 1992) o trastornos motores extrapiramidales persistentes, como los movimientos coreo-atetoides (Bauer, 1993), conocidos entre los adictos como "baile del crack".

Los estudios mediante tomografía por emisión de positrones (PET) han detectado alteraciones funcionales persistentes en el metabolismo dopaminérgico del estriado y en el metabolismo de la glucosa cerebral, en dependientes de cocaína (Baxter y cols., 1992; Volkow y cols., 1992a).

\section{DETERIORO COGNITIVO INDUCIDO POR COCAÍ- NA}

El consumo excesivo ("heavy") de cocaína, definido como igual o mayor que 2 gramos a la semana, puede dar lugar a déficits persistentes en las habilidades necesarias para las tareas escolares o laborales, como la atención, planificación, razonamiento y enlentecimiento del tiempo de reacción.

Las secuelas cognitivas asociadas al consumo de cocaína son los déficits de atención, memoria declarativa, funciones espaciales y velocidad psicomotriz. Strickland y cols., (1993) encontraron regiones de hipoperfusión en áreas frontales, periventriculares y/o temporales, que correlacionaron con déficits cognitivos de atención, concentración, nuevos aprendizajes, memoria visual y verbal, producción de palabras e integración visuo-motora.

Los estudios que evalúan los efectos del consumo de alcohol, sobre el funcionamiento cognitivo, han 
identificado bajos rendimientos en razonamiento abstracto, formación de conceptos, habilidades visuoespaciales, adquisición de aprendizaje y memoria a corto plazo (Goldman, 1983).

Tales déficits cognitivos producen un retraso en la adquisición de las habilidades para rechazar las invitaciones a consumir, lo cual puede aumentar el riesgo de recaída en los pacientes en recuperación. Además, un bajo funcionamiento cognitivo puede influir en un menor rendimiento de las intervenciones psicoterapéuticas (Carpenter y Hittner, 1997).

Los estudios efectuados con abusadores de cocaína han detectado déficits de memoria verbal y aprendizaje asociativo (Ardila, Rosselli y Strumwaser, 1991); de concentración, memoria verbal, resolución de problemas y habilidades de abstracción (O'Malley y cols, 1992); de atención, concentración, nuevos aprendizajes, memoria, producción de palabras e integración visuo-motora (Stickland y cols., 1993) y también en la capcidad de abstracción e integración visuo-motora, en abusadores de cocaína y alcohol (Beatty y cols., 1995). Muchos abusadores de cocaína lo son también de alcohol y además, los trastornos psiquiátricos comórbidos, particularmente la depresión, pueden estar asociados también a deterioro cognitivo.

Mediante la batería neuropsicológica de LuriaNebraska se han detectado déficits en el rendimiento, que han podido ser relacionados con el consumo de cocaína, a lo largo de toda la vida del paciente y con su nivel educativo (Carpenter y Hittner, 1997), sugiriendo además, que el impacto del abuso de sustancias sobre el rendimiento cognitivo depende de los tests utilizados.

En estudios con animales se ha comprobado que la cocaína puede producir neurotoxicidad (Gawin y Ellinwood, 1988). En humanos se ha detectado vasculitis cerebral, hemorragia intracraneal y una disminución de la señal de T1 en la resonancia magnética, que puede reflejar degeneración neuronal en consumidores severos de cocaína.

Por tanto, el abuso de cocaína produce neurotoxicidad difusa, con posibles alteraciones neuropsicológicas subclínicas, bien sea por efecto neurotóxico directo, o bien por microinfartos cerebrales múltiples, secundarios a los cambios hemodinámicos inducidos por cocaína (Gawin y Ellinwood, 1988; O'Malley y cols., 1992).

Otros estudios con poliabusadores de sustancias no han encontrado asociación entre el abuso de estimulantes y el deterioro neuropsicológico (Grant y cols., 1978).

O'Malley y cols. (1992) han encontrado deterioro neuropsicológico en un grupo de 20 abusadores de cocaína, seleccionados de manera que no presentaran abuso de alcohol ni otras drogas, ni otras posibles causas de deterioro neuropsicológico. El 70\% eran fumadores de base libre y el 30\% restante consumían la cocaína por vía inhalatoria.

El $50 \%$ de los abusadores de cocaína presentaban deterioro, comparados al $15 \%$ de los sujetos control. El peor rendimiento apareció en los tests de dígitos, aritmética y memoria de almacenamiento, lo cual sugiere que el abuso crónico de cocaína estaría asociado a problemas de concentración y memoria; presentando además un bajo rendimiento en la resolución de problemas no verbales y en la capacidad de abstracción.

La intensidad y frecuencia del consumo total de cocaína correlacionó con el deterioro neuropsicológico, lo cual sugiere que el propio abuso de cocaína tiene una relación directa con el funcionamiento neuropsicológico. Los pacientes fueron evaluados entre 6 y 60 días después del cese del consumo de cocaína. Dado que las puntuaciones de aritmética eran peores cuanto más reciente era el consumo, sugiere que el deterioro de la atención puede mejorar cuanto mayor sea el tiempo de abstiencia de cocaína. (O'Malley y cols., 1992).

Un estudio con PET ha reportado disrupción de las vías GABA-aminérgicas en pacientes que se encontraban en abstinencia aguda de cocaína. La alteración de la dopamina afecta a la memoria procedural, pero no a los procesos de memoria declarativa.

La memoria procedural consistiría en aprender un acto motor, como cambiar de pedales en la conducción de vehículos. Su sustrato neuro-anatómico serían las estructuras subcorticales dopaminérgicas. La memoria declarativa, como aprender la lista de la compra, tendría que ver con estructuras como los lóbulos temporales y el hipocampo.

Tras el cese del consumo de cocaína mejoraría la rapidez y la duración del aprendizaje que depende de la memoria procedural, pero empeoraría la memoria declarativa. Los abusadores de cocaína presentan un aumento de la memoria procedural, tal vez debido a un hipersensibilidad de los receptores dopaminérgicos D1 y D2. La hipersensibilidad de receptores dopaminérgicos sería un fenómeno adaptativo a la deplección de dopamina, inducida por cocaína (Van Gorp y cols., 1999).

\subsection{DETERIORO DE LA VISIÓN EN COLOR}

La dopamina se encuentra en elevadas concentraciones en la retina, donde juega un importante papel en la visión de los colores. Pacientes recientemente desintoxicados cometen un mayor número de errores en la visión de los colores azules y amarillos. Dichos cambios en la visión de los colores podrían ser secundarios al abuso de cocaína y persistentes (Desai y cols., 1997). 


\subsection{EFECTOS DE LA COCAÍNA SOBRE EL CEREBRO EN DESARROLLO}

La exposición a la cocaína durante el desarrollo fetal puede conducir a sutiles pero significativos déficits neuropsicológicos, durante la infancia, que dificulten la capacidad de concentración y la adaptación al medio escolar.

Durante el período prenatal, la exposición a la cocaína conlleva más problemas conductuales, debido a que son niños que presentan más agresividad, impulsividad y dificultades para concentrarse, mantener la atención focalizada y no distraerse, a la vez que son más ansioso y depresivos.

Durante el desarrollo cerebral, la unión de la dopamina a los receptores dopaminérgicos D1 produce la inhibición del crecimiento de las dendritas. Sin embargo, los cerebros expuestos a la cocaína presentan alteraciones en el desarrollo neuronal que han sido estudiadas en el córtex cingulado anterior, una estructura implicada en la atención y el aprendizaje, en el que las dendritas presentan un crecimiento del 30\%$50 \%$ mayor, estableciendo más conexiones con otras neuronas, lo cual tendrá posteriormente repercusiones en el funcionalismo dopaminérgico. Dicho cambio en los receptores D1 podría explicar incluso que el trastorno por déficit de atención, debido a la exposición fetal a la cocaína, no tenga una buena respuesta a los estimulantes, como metilfenidato, a diferencia del otro trastorno por déficit de atención primario (Vogel, 1997).

\section{RESUMEN FINAL Y CONCLUSIONES}

Los abusadores crónicos de cocaína presentan déficits neurológicos, sobretodo del tipo hipofrontalidad y disfunciones en los ganglios basales, que cursan con una disminución del metabolismo del córtex frontal y suelen ir acompañados de deterioro cognitivo, déficits neuropsicológicos, impulsividad, desinhibición conductual, déficit de introspección, de atención y trastornos motores persistentes; los cuales han sido detectados también en pacientes dependientes de otros psicoestimulantes.

Además, el consumo crónico de cocaína conduce a un estado de hipodopaminergia, asociada a bajos niveles de serotonina cerebral, que pueden estar en relación con los estados de anhedonia y desmotivación que, junto con el deterioro neuropsiquiátrico que acompaña al abuso de cocaína, aumentan la vulnerabilidad para las recaídas, incluso tras un prolongado período de abstención de cocaína.

Las técnicas de neuroimagen permiten detectar alteraciones estructurales, del tipo atrofia del córtex frontal y ganglios basales, así como también funciona- les, del tipo déficits en la perfusión cerebral en áreas frontales, periventriculares y témporo-parietales.

La vasoconstricción de la circulación cerebral y coronaria, combinada con un aumento de la agregación plquetaria, inducidas por cocaína, pueden contribuir a los episodios isquémicos e infartos cerebrales, que comprometen el metabolismo energético cerebral, que puede sumarse, en ocasiones, a hemorragia subaracnoidea o intracerebral. Los déficits en la perfusión sanguínea cerebral pueden persistir durante 3 a 6 meses, después de la desintoxicación de cocaína.

La exposición a la cocaína durante el desarrollo fetal puede conducir a sutiles pero significativos déficits neuropsicológicos, durante la infancia, que dificulten la capacidad de concentración y la adaptación al medio escolar.

Estudios efectuados con PET y SPECT han detectado (1) una disminución de la tasa metabólica en regiones frontales y subcorticales (London y cols., 1990; Volkow y cols., 1992; 1996); (2) una regulación descendente de los receptores dopaminérgicos post-sinápticos, que se recupera con la abstinencia (Volkow y cols., 1990); (3) una disminución de la liberación de dopamina en el estriado asociada al aumento de liberación de dopamina en el tálamo (Volkow y cols., 1997) (4) una hipoperfusión cerebral generalizada (Volkow y cols., 1998; Holman y cols., 1993; Weber y cols., 1993), sobretodo en el córtex frontal (Volkow y cols., 1992) (5) menos alteraciones en la perfusión cerebral del lóbulo frontal en las mujeres que en los hombres dependientes de cocaína (Chang y cols., 1999).

También se han detectado indicadores de lesión neuronal y proliferación glial (mediante resonancia mangnética espectroscópica), indicadores de alteraciones persistentes que pueden estar en relación con los déficits cognitivos y de aprendizaje que van a dificultar que el paciente dependiente de cocaína pueda beneficiarse de una psicoterapia convencional.

Todo ello puede conducir a un replanteamiento de las intervenciones terapéuticas empleadas hasta ahora, con la finalidad de mejorar su eficacia.

\section{BIBLIOGRAFIA}

(1) Ardila A, Rosselli M, Strumwasser S: Neuropsychological deficits in chronic cocaine abusers. International Journal of Neuroscience 1991; 57: 73-79.

(2) Bartzokis G, Beckson M, Ling W: Clinical and MRI evaluation of psychostimulant neurotoxicity. In: Majewska MD (Ed.) Neurotoxicity and neuropathology associated with cocaine abuse. NIDA Research Monogrph 163. U.S. Department of Health and Human Services. National Institutes of Health. Rockville. 1996 (p. 300-317). 
(3) Bauer LO: Motoric signs of CNS dysfunction associated with alcohol and cocaine withdrawal. Psychiatry Res. 1993; 47:69-77.

(4) Baxter LR, Melega WP, Yu DC, Barrio JR, Huang S, Phelps ME: Abnormal presynaptic dopamine neuron function in heavy cocaine abusers determined with PET and [18F] Fluro-Dopa". Paper presented at the $31^{\text {st }}$ annual meeting of the american College of Neuropsychopharmacology, San Juan, Puerto Rico, December 6-10, 1992.

(5) Beatty WW, Katzung VM, Moreland VJ, Nixon SJ: Neuropsychological performance of recently abstinent alcoholics and cocaine abusers. Drug and Alcohol Dependence 1995; 37: 247-253.

(6) Breiter HC, Gollub RL, Weisskoff RM, Kenedy DN, Makris N, Berke JD, Goodman JM, Kantor HL, Gastfirend DR, Riorden JP, Mathew RT, Rosen RB, Hyman SE: Acute effects of cocaine on human brain activity and emotion. Neuron 1997; 19:591-611.

(7) Carpenter KM, Hittner JB: Cognitive impairmant among the dually-diagnosed: substance use history and depresive symptom correlates. Addcition 1997; 92:747-759.

(8) Chang L, Ernst T, Strickland T, Mehringer CM: Gender effects on persistent cerebral metabolite changes in the frontal lobes of abstinent cocaine users. Am. J. Psychiatry 1999; 156: 716-722.

(9) Childress AR: Brain imaging during drug craving states. In: Harris $L(E d)$. Problems of drug dependence. NIDA Research. Monograph 153. NIH Pub. No. 95-3883. Washington, DC: Supt. Of Docs., U.S. Govt. Print. Off., 1995.

(10) Childress AR; Mozley PD; McElgin W; Fitzgerald J; Reivich M; O'Brien CP: Limbic activation during cueinduced cocaine craving. Am. J. Psychiatry 1999; 256:11-18.

(11) Desai P, Roy M, roy A, Brown S, Smelson D: Impaired color vision in cocaine-withdrawn patients. Arch. Gen. Psychiatry 1997; 54: 696-699.

(12) Ellison G, Irwin S, Keys A, Noguchi K, Sulur G: The neurotoxic effects of continuous cocine and amphetamine in habenula: implications for the substrates of psychosis. In: Majewska MD (Ed.) Neurotoxicity and neuropathology associated with cocaine abuse. NIDA Research Monogrph 163. U.S. Department of Health and Human Services. National Institutes of Health. Rockville. 1996 (p. 117-145).

(13) Gawin FH, Ellinwood EH. Cocaine and other stimulants: Actions, abuse and treatment. N. Engl. J. Med. 1988; 1173-1182.

(14) Goldman MS: Cognitive impairment in chronic alcoholics: some cause for optimism. American Psychologist 1983; 38:1045-1054.

(15) Grant S, London ED, Newlin DB, Villemagne VL, Liu X, Contoreggi C, Phillips RL, Kimes AS, Margolin A. Activation of memoty circuits during cue-elicited cocaine craving. Proc. Natl. Acad. Sci. USA 1996; 93:12040-12045.
(16) Guardia J; Catafau AM; Batlle F; Martían JC; Segura L; Gonzalvo B; Prat G; Carrió I; Casas M: Striatal dopaminergic D2 receptor density measured by [ ${ }^{123}$ ] lodobenzamide SPECT in the prediction of treatment outcome of alcohol-dependent patients. Am. J. Psychiatry. 2000; 157:127-129.

(17) Herning RI, King DE: EEG and evoked potentials alterations in cocaine-dependent individuals. In: Majewska MD (Ed.) Neurotoxicity and neuropathology associated with cocaine abuse. NIDA Research Monogrph 163. U.S. Department of Health and Human Services. National Institutes of Health. Rockville. 1996 (p. 203-223).

(18) Herning RI, King DE, Better W, Cadet JL: Cocaine dependence: A clinical syndrome requiring neuroprotection. Annals of the New York Academy of Sciences 1997; 825: 323-327.

(19) Hitri A, Casanova MF, kleinman JE, Wyatt RJ: Fewer dopamine transporter receptors in the prefrontal cortex of cocaine users. Am. J. Psychiatry 1994; 151: 10741076.

(20) Holman BL, Carvalho PA, Mendelson J, Teoh SK, Nardin $R$, Hallgring $E$, Hebben N, Johnson KA: Brain perfusion is abnormalin cocaine-dependent polydrug users: $A$ study using technetium-99m-HMPAO and SPECT. J. Nucl. Med. 1991; 32:1206-1210.

(21) Holman BL, Mendelson J, Garada B, Teoh SK, Hallgring E, Johnson KA, Mello NK: Regional cerebral blood flow improves with treatment in chronic cocaine polydrug users. J. Nucl. Med. 1993; 34:723-727.

(22) Holcomb HH; Cascella NG; Thaker GK; Medoff DR; Dannals RF; Tamminga CA: Functional sites neuroleptic drug action in the human brain: PET/FDG studies with and without haloperidol. Am. J. Psychiatry 1996; 153:41-49.

(23) Hommer DW: Functinal Imaging of craving. Alcohol Research and Health 1999; 23: 187-196.

(24) Jacobsen LK, Staley JK; Malison RT, Zoghbi SS, Seibyl JP, Kosten TR, Innis RB: Elevated central serotonin Transporter binding availability in acutely abstinent cocaine-dependent patients. Am. J. Psychiatry 2000; 157: 1134-1140.

(25) Johanson CE, Schuster Ch R: Cocaine. In Bloom \& Kupfer DJ (Eds.) Psychopharmacology: The Fouth Generation of Progress. Raven Press, Ltd., New York 1995 (p. 1685-1697).

(26) Kaufman MJ, Levin JM, Ross Mh, Lange N, Rose SL, Kukes TJ, Mendelson JH, Lukas SE, Cohen BM, Renshw PF: Cocaine-induced cerebral vasoconstriction detected in humans with magnetic resonance angiography. J.A.M.A. 1998; 279:376-280.

(27) Khantzian EJ: The self-medication hypothesis of addictive disorders: focus on heroin and cocaine dependence. Am. J. Psychiatry 1985; 142:1259-1264.

(28) Kosten TR, Malison R, Wallace E: Neuropsychological abnormalities in cocaine abusers: possible correlates in SPECT neuroimaging. In: Majewska MD (Ed.) Neurotoxicity and neuropathology associated with 
cocaine abuse. NIDA Research Monogrph 163. U.S. Department of Health and Human Services. National Institutes of Health. Rockville. 1996 (p. 175-192)

(29) Langendorf FG, Anderson DC, Tupper DE, Rottenberg DA, Weisman ID: Brain atrophy and chronic cocaine abuse: background and work in progress. In: Majewska MD (Ed.) Neurotoxicity and neuropathology associated with cocaine abuse. NIDA Research Monogrph 163. U.S. Department of Health and Human Services. National Institutes of Health. Rockville. 1996 (p. 27-42).

(30) Laruelle M; Abi-Dargham A; van Dyck CH; Rosenblatt W; Zea-Ponce Y; Zoghbi SS; Baldwin RM; Charney DS; Hoffer PB; Kung HF; Innis R: SPECT imaging of striatal dopamine release aftrer amphetamine challenge. $\mathbf{J}$. Nucl. Med. 1995; 36:1182-1190.

(31) Little KY, McLaughlin DP, Zhang L, McFinton PR, Dalack GW, Cook EH, Cassin BJ, Watson SJ. Brain dopamine transporter messenger RNA and binding sites in cocaine users. Arch. Gen. Psychiatry 1998; 55: 793799.

(32) Little KY, Zhang L, Desmond T, Frey KA, Dalack GW, Cassin BJ: Striatal dopaminergic abnormalities in human cocaine users. Am J Psychiatry 1999; 156: 238-245.

(33) London ED, Stapleton JM, Phillips RL, Grant SJ, Villemagne VL, Liu X, Soria R: PET studies of cerebral glucose metabolism: acute effects of cocaine and longterm deficits in brains of drug abusers. In: Majewska $M D$ (Ed.) Neurotoxicity and neuropathology associated with cocaine abuse. NIDA Research Monogrph 163. U.S. Department of Health and Human Services. National Institutes of Health. Rockville. 1996 (p. 146-157).

(34) London ED, Cascella NG, Wong DF, Phillips RL, Dannals RF, Links JM, Herning R, Grayson R, Jaffe JH, Wagner $\mathrm{HN}$ : Cocaine-induced reduction of glucose utilization in human brain. A study using positron emission tomography an [fluorinc 18]fluoro-deoxyglucose. Arch. Gen. Psychiatry 1990; 47:567-574.

(35) Maas LC, Lukas SE, Kaufman MJ, Weiss RD, Daniels SI, Rogers VW, Kukes TJ, Renshaw PF: Functional Magnetic Resonance Imaging of Human Brain Activation During Cue-Induced Cocaine Craving. Am. J. Psychiatry 1998; 155:124-126.

(36) Majewska MD: Cocaine addictio as a neurological disorder: implications for treatment. In: Majewska MD (Ed.) Neurotoxicity and neuropathology associated with cocaine abuse. NIDA Research Monogrph 163. U.S. Department of Health and Human Services. National Institutes of Health. Rockville. 1996 (p. 1-26).

(37) Malison RT, Best SE, Van Dyck CH, McCance EF, Wallace EA, Laruelle M, Baldwin RM, Seibyl JP, Price LH, Kosten TR, Innis RB: Elevated striatal dopamine transporters during acute cocaine abstinence as measured by b-CIT SPECT. Am. J. Psychiatry 1998; 155: 832-834.
(38) McCance-Katz EF, Price LH, McDougle CJ, Kosten TR; Black JE, Jatlow PI: Concurrent cocaine-ethanol ingestion in humans: Pharmacology, physiology, behavior, and the role of cocaethylene. Psychopharmacology 1993; 111:39-46.

(39) Morgan JM, Cascella NG, Stapleton JM, Phillips RL, Yung BCK, Wong DF, Shaya EK, London ED: Sensitivity to subjective effects in cocaine drug abusers: Relationship to cerebral ventricle size. Am. J. Psychiatry 1993; 150:1712-1717.

(40) O'Malley S, Adams M, Heaton RK, Gawin FH: Neuropsychological impairment in chronic cocaine abusers. Am. J. Drug Alcohol Abuse 1992; 18:131-144.

(41) Pascual-Leone A, Dhuna A, Anderson DC: Cerebral atrophy in habitual cocaine abusers. Neurology 1991; 18:131-144.

(42) Piazza PV, Marinelli M, Rougé-Pont F, Deroche V, Maccari S, Simon H, Le Moal M: Stress, glucocorticoides, and mesencephalic dopaminergic neurons: a pathophysiological chain determining vulnerability to psychostimulant abuse. In: Majewska MD (Ed.) Neurotoxicity and neuropathology associated with cocaine abuse. NIDA Research Monogrph 163. U.S. Department of Health and Human Services. National Institutes of Health. Rockville. 1996 (p. 277-299).

(43) Rounsaville BJ, Foley Anton S, Caroll K, Budde D, Prusoff BA, Gawin FH: Psychiatric diagnoses of treatment-seeking cocaine abusers. Arch., Gen Psychiatry 1991; 48:43-51.

(44) Staley JK, Hearn WL, Ruttenberg AJ, Wetli CV, Mash DC: High affinity cocaine recognition sites on the dopamine transporter are elevated in fatal cocaine overdose victims. J. Pharmacol. Exp. Ther. 1994; 271:1678-1685.

(45) Strickland TL y cols.: Cerebral perfusion and neuropsychological consequences of chronic cocaíne use. Journal of Neuropsychiatry 1993; 5:419-427.

(46) Strickland TL, Stein RA, Khalsa-Denison ME, Andre k: Neuropsychological effects of chronic cocaine use following sustained abstinence. Archives of Clinical Neuropsychology 1996; 11:456-457.

(47) Van Gorp WG; Wilkins JN, Hinkin ChH, Moore LH, Hull J, Horner MD, Plotkin D: Declarative and procedural memory functining in abstinent cocaine abusers. Arch. Gen. Psychiatry 1999; 56:85-89.

(48) Vogel G: Cocaine wreaks subtle damage on developing brains. Science 1997; 278:38-40.

(49) Volkow ND; Mullani N, Gould KL, Adler S, Krajewski K: Cerebral blood flow in chronic cocaine abusers: A study with positron emission tomography. Br. J. Psychiatry 1988; 151:641-648.

(50) Volkow ND; Fowler JS; Wolf AP, Schlyer D, Shiuc CY, Alpert R, Dewey SL, Logan J, Bendriem B, Christman D, Hitzeman R, Henn F: Effects of chronic cocaine abuse on postsynaptic dopamine receptors. Am. J. Psychiatry 1990; 147:719-724.

(51) Volkow ND; Fowler JS; Wolf AP; Hitzemann R; Dewey $\mathrm{S}$; Alpert $\mathrm{R}$; Hoff $\mathrm{A}$ : Changes in brain glucose 
metabolism in cocaine dependece and withdrawal.

Am. J. Psychiatry 1991a; 148:621-626.

(52) Volkow ND, Fowler JS, Wolf AP: Use of positron emission tomography to study cocaine in the human brain. In: Rapaka RS, Makriyannis A, Kuhar MJ (Eds.) Emerging technologies and new directions in drug abuse rresearch. NIDA Research Monogrph 112. U.S. Department of Health and Human Services. National Institutes of Health. Rockville.1991b; (p. 168-179).

(53) Volkow ND, Hitzemann R, Wang G-J, Fowler JS, Wolf AP, Dewey SL, Handlesman L: Long-term frontal brain metabolic changes in cocaine abusers. Synapse 1992a; 11: 184-190.

(54) Volkow ND, Fowler JS, Logan J, Wang G-J, Hitzemann R, MacGregor R, Dewey SL, Wolf AP: Decreased binding of 11-C-Cocaine in brain of cocaine addicts. $\mathbf{J}$. Nucl. Med. 1992b; 33:888.

(55) Volkow ND; ; Fowler JS; Wang GJ; Hitzemann R; Logan J;Schlyer D; Dewey S; Wolf AP: Decreased dopamine D2 receptor availability is associated with reduced frontal metabolism in cocaine abusers. Synapse 1993; 14: 169-177.

(56) Volkow ND; Ding YS; Fowler JS; Wang GJ; Logan J; Gatley JS; Dewey S; Ashby C; Liebermann J; Hitzemann R; Wolf AP: Is Methylphenidate like cocaine? Arch. Gen. Psychiatry 1995b; 52: 456-463.

(57) Volkow ND; Wang GJ; Fowler JS; Gatley SJ; Logan J; Dewey SL; Hitzemann R; Lieberman J: (Relationship between psychostimulant-induced "high" and dopamine transporter occupancy. Proc. Nat. Acad. Sci. USA 1996a; 93: 10388-10392.

(58) Volkow ND; Ding Y-S; Fowler JS; Wang GJ: Cocaine addiction: hypothesis derived from imaging studies with PET. J. Addict. Dis 1996b; 15:55-71.
(59) Volkow ND; Wang GJ; Fowler JS; Hitzemann R; Pappas N; Pascani K; Wong C: Gender differences in cerebellar metabolism: test-retest reproductibility. Am. J. Psychiatry 1997a; 154: 119-121.

(60) Volkow ND; Wang GJ; Fischman MW; Foltin RW; Fowler JS; Abumrad JS; Vitkun NN; Logan J; Gatley SJ; Pappas N; Hitzemann R; Shea K: Relationship between subjective effects of cocaine and dopamine transporter occupancy. Nature 1997b; 386: 827-830.

(61) Volkow ND, Gur RC, Wang GJ, Fowler JS, Moberg PJ, Ding YS, Hitzemann R, Smith G, Logan J: Association between decline in brain dopamine activity with age and cognitive and motor impairment in healthy individuals. Am. J. Psychiatry 1998; 155:344-349.

(62) Volkow ND, Wang GJ, Fowler JS, Logan J; Gatley SJ; Gifford A; Hitzemann R; Ding YS; Pappas N: Prediction of reinforcing responses to psychostimulants in humans by brain dopamine D2 receptors levels. Am. J. Psychiatry. 1999a; 156:1440-1443.

(63) Volkow ND, Wang GJ, Fowler JS, Hitzemann R, Angrist B; Gatley SJ; Logan J; Ding YS; Pappas N: Association of methylphenidate-induced craving with changes in right striato-orbitofrontal metabolism in cocine abusers: implications in addiction. Am. J. Psychiatry 1999b; 156:19-26.

(64) Volkow ND, Fowler JS, Wang G-J: Imaging studies on the role of dopamine in cocine reinforcement and addiction in humans. Journal of Psychopharmacology 1999c; 13:337-345.

(65) Volkow ND, Wang GJ, Fowler JS, Logan J, Gatley SJ, Wong Ch, Hitzemann R, Pappas N: Reinforcing effects of psychostimulants in humans are associated with increases in brain dopamine and occupancy of D2 receptors. J. Pharmacol. Exper. Ther. 1999d; 291. 409415. 
Tabla 1: Cambios en la actividad de diversas regiones cerebrales en estado de "craving" de cocaína, mediante neuroimagen funcional. Adaptado de Hommer y cols. (1999).

\begin{tabular}{|c|c|c|c|c|c|c|c|}
\hline $\begin{array}{l}\text { Técnica de imagen } \\
\text { utilizada }\end{array}$ & $\begin{array}{l}\text { Nucleo } \\
\text { Accumbens }\end{array}$ & $\begin{array}{l}\text { Núcleo } \\
\text { Caudado }\end{array}$ & Tálamo & Amígdala & $\begin{array}{l}\text { Córtex } \\
\text { orbitario }\end{array}$ & $\begin{array}{c}\text { Córtex } \\
\text { frontal } \\
\text { dorso-lateral }\end{array}$ & $\begin{array}{c}\text { Córtex } \\
\text { cingulado } \\
\text { anterior }\end{array}$ \\
\hline $\begin{array}{l}\text { PET con FDG } \\
\text { (Grant y cols., 1996) }\end{array}$ & & & & $\uparrow$ & $\uparrow$ & $\uparrow$ & $\uparrow$ \\
\hline $\begin{array}{l}\text { PET con O'15 } \\
\text { (Childress y cols., 1999) }\end{array}$ & & $\downarrow$ & & $\uparrow$ & & $\uparrow$ & $\uparrow$ \\
\hline $\begin{array}{l}\text { RMF } \\
\text { (Maas y cols., 1998) }\end{array}$ & & & & & $\uparrow$ & & $\uparrow$ \\
\hline $\begin{array}{l}\text { RMF } \\
\text { (Breiter y cols., 1997) }\end{array}$ & $\uparrow$ & $\uparrow$ & $\uparrow$ & $\downarrow$ & & $\uparrow$ & $\uparrow$ \\
\hline $\begin{array}{l}\text { PET / raclopride } C^{11} \\
\text { (Volkow y cols., 1999) }\end{array}$ & & $\downarrow$ & $\uparrow$ & & & & \\
\hline $\begin{array}{l}\text { PET: Tomografía por emisión de } \\
\text { FDG: Fluoro-desoxiglucosa } \\
\text { RMF: Resonancia magnética fur }\end{array}$ & & & & & & & \\
\hline
\end{tabular}

Tabla 2: Regiones cerebrales implicadas en el "craving" y sus principales funciones. (Adaptado de Hommer y cols., 1999).

\section{REGIÓNES CEREBRALES FUNCIÓN}

\section{Subcorticales}

Circuíto estriado-tálamo-cortical Conecta áreas del córtex relacionadas con el estriado, el cual a su vez proyecta hacia el tálamo, a través del pálido. Dicha información se combina en el tálamo con la que procede de áreas corticales relacionadas y finalmente la envía de regreso al córtex frontal.

Selecciona una respuesta (emocional, cognitiva, motora) entre las diversas respuestas potenciales, basadas en el contexto conductual.

Núcleo Accumbens

(estriado ventral)

Conectado a los sistemas límbicos y córtex prefrontal orbitario. Relacionado con la emoción, motivación y recompensa.

Núcleo Caudado

Conectado al córtex prefrontal medial y lateral.

(estriado dorsal)

Relacionado con cognición y motivación.

Tálamo

Relevo de información entre las regiones corticales y otras áreas cerebrales, incluyendo el estriado.

Amígdala

Aprendizaje de estímulos predictores de recompensa o castigo.

Respuesta de miedo.

\section{Corticales}

Córtex prefrontal

Memoria de trabajo. Planificación y preparación motora Inhibición de la conducta inapropiada al contexto.

Córtex fronto-orbitario

Olfación, evaluación de estímulos motivacionalmente significativos, inhibición conductual, cambios de conducta.

Córtex dorso-lateral

Memoria de trabajo espacial y cognición

Córtex cingulado anterior

Atención selectiva, motivación y emoción.

Córtex insular

Función visceral, olfación, gusto y emoción 
